\title{
HISTIOSTOMA BLOMQUISTI N. SP. (ACARI: ASTIGMATA: HISTIOSTOMATIDAE), A PHORETIC MITE OF THE RED IMPORTED FIRE ANT, SOLENOPSIS INVICTA BUREN (HYMENOPTERA: FORMICIDAE)
}

\author{
Stefan WIRTH ${ }^{1}$ and John C. MOSER ${ }^{2}$ \\ (Received 25 June 2010; accepted 13 September 2010; published online 30 September 2010) \\ ${ }^{3}$ Musenun für Naturkunde, Leibniz-Institut filr Evolutions- und Biodinersitaitsforschung an der Humboldt-Universitat zu Berlin, Livalidenstraße \\ 43, 10115 Berlin. wirthsteforueb.de (corresponding author)

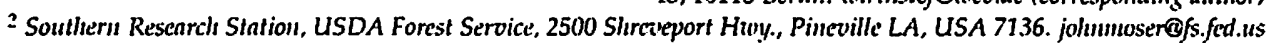

\begin{abstract}
The new species Histiostoma blomquisti n. sp., associated with the Red Imported Fire Ant, Solenopsis invictn, is described by its deutonymph. A putative adult female is depicted. The deutonymphs only attach to female alates, dealates and queens of $S$. invictn. While queens may be covered by more than 200 deutonymphs over their entire bodies, the numbers of deutonymphs substantially differed between alates, dealates and queens, which are the preferred carriers, and the males and workers, which are usually not the phoretic hosts of these deutonymphs. It is assumed that the large amount of deutonymphs on queens may be a consequence of special conditions during nest foundings of monogyne colonies. Presence of deutonymphs apparently stimulates the cleaning behavior in workers; however deutonymphs are not removed during this procedure. This may be a consequence of chemical components produced in the opisthonotal glands of astigmatid mites that allow the mite to repel cleaning workers and remain strongly adhered to its carrier. It is unknown whether or not these mites affect the vitality of fire ant colonies.
\end{abstract}

KEYWORDS - Solenopsis invictn; Red Imported Fire Ant; Histiostoma blomquisti n. sp., alates; dealates; queens; deutonymphs; cleaning behavior; opisthonotal glands; lateral oil glands; Histiostomatidae; Astigmata; allomones

\section{INTRODUCTION}

Many arthropods are known to exist in fire ant nests. Collins and Markin (1971) reported more than 50 insect species from nests of Solenopsis spp. Ant associates evolved different kinds of mechanisms to allow integration into ant nests: morphological mimicry, defensive chemical secretions and chemical mimicry (Vander Meer and Wojcik, 1982). Another mechanism was discovered for the beetle Martineziana dutertrei (Scarabidae), which acquires ant-nest-specific hydrocarbons (Vander and Wojcik,
1982) and is a common nest inhabitant of S. invictn (personal observation S. Wirth). Little is known regarding the biology of mites from nests of S. invicta; however, several of the mites phoretic on female alates and dealates have been recently described (Ebermann and Moser, 2008, Khaustov and Moser, 2008).

One of these phoretic mites is Histiostoma blomquisti n. sp., whose deutonymphs are usually found attached to female alates and dealates. (Solokov et al., 2003) found them less frequently phoretic on female alates than on dealates. They 
Wirth S. and Moser J. C.

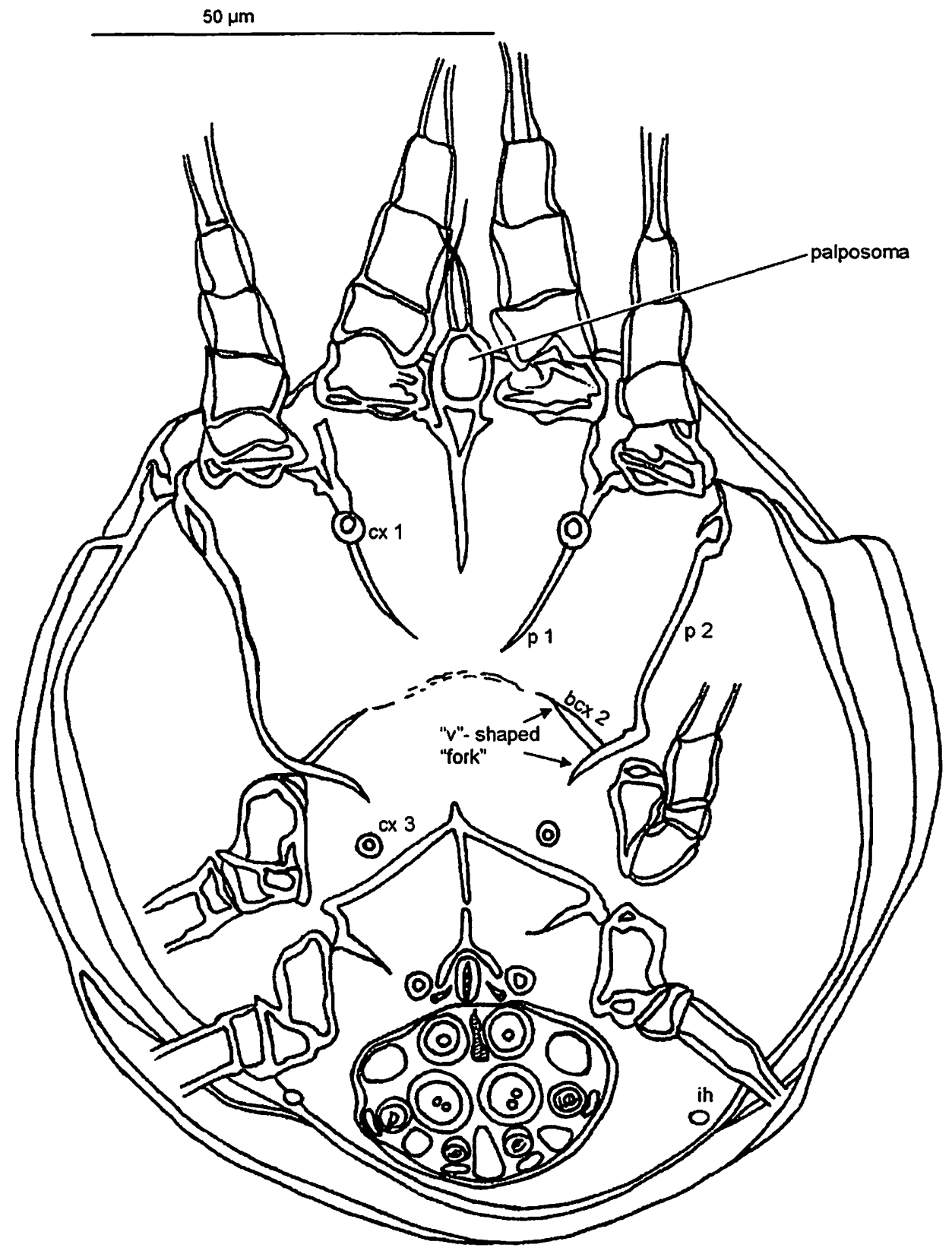

FIGURE 1: Deutonymph of $H$. blomquisti $\mathrm{n}$. $\mathrm{pp}$. in ventral view; $\mathrm{cx} 1, \mathrm{cx} 3=$ conoids; $\mathrm{p} 1, \mathrm{p} 2, \mathrm{bcx2}=$ apodemes 
did not discover deutonymphs associated with $S$. invicta workers. Solokov et al. observed these deutonymphs attached to their carrier's posterior region of the gaster. Moser and Blomquist (personal communication) discovered that the numbers of phoretic mite species attached to alates varied during different periods in a year. Several of the mites species found associated with $S$. invicta peaked in February and again from May through August (Fig. 6).

Solenopsis invicta workers react aggressively to nest-invading organisms such as arthropods in order to keep their nests clean (Vander Meer and Wojcik, 1982). When mites attach to workers of leafcutting ants, such as Atta texana, this stimulates a cleaning behavior by other workers (Wirth and Moser, 2008).

In this study we note that S. invicta workers clean queens and alates when $H$. blomiquisti n. sp. are attached to alates and nest queens. The opisthonotal glands of oribatid and astigmatid mites produce components with different functions such as pheromones, allomones and fungicides (Kuwahara, 1991; Kuwahara et al., 1989). The effects by these types of components were also studied in simple behavioral experiments here. A fungicide effect on histiostomatids in laboratory cultures can be commonly observed (Wirth, 2009).

Here we note for the first time possible fungicide allomone effects of $H$. bloniquisti $\mathrm{n}$. sp.. The allomone function in astigmatid mites is for example poorly studied; therefore, a deterring effect between deutonymphs and S. invicta workers is described.

Solenopsis invicta originally lived in South America and was first observed in the southern USA (Creighton, 1930). This pest affects the native ecosystem by being competitive to native species such as the native fire ants Solenopsis xyloni and Solenopsis geninata. The control of $S$. invicta has been ineffective. Natural enemies and pathogens, such as the decapitating parasitoid fly, Pseudncteon curvatus (Vazquez et al., 2006) and the soil fungus, Benuverin bassiann (Siebeneicher et al., 1992), have been studied as potential means of biological control. Solokov et $\mathrm{al}$. (2003) theorized that $H$. blomquisti $\mathrm{n}$. sp. might act as a vector to introduce pathogens into the ant nests; however, most of this mite's biology is still unknown.

\section{MATERIAL AND METHODS}

Male and female alates of $S$. invicta were collected between March 13 and April 14 2009, in Pineville,Louisiana, USA, from 34 different nests. Ant alates were asperated directly from nest surfaces as they prepared to fly during mating flights. Additonal alates were collected after they had been exposed within the nests. Collected ants were placed in $99 \%$ ethanol and the mite deutonymphs, which mostly remained attached, were counted. Dealates were not studied.

Queens were collected by isolating whole colonies. Major ant mounds on the ground surface were collected quickly with a shovel to prevent the colony from fleeing to lower levels of the nest. The nest material was placed into a large plastic container with Teflon-coated walls which prohibited the ants from escaping.

In the laboratory, each container was slowly filled with water to flood the nest. Alates, workers, larvae, pupae, and the nest queen aggregated as a compact crawling mass on the water surface, where they were easily extracted by a small, aquarium fishing net. Each ant mass was placed into separate small, plastic boxes $(6 \times 9 \times 4.5 \mathrm{~cm})$, whose interior walls had been treated with liquid Teflon and a sprinkle of baby powder to prevent colonies from escaping.

Behaviors of the mites and ants were either observed by putting the entire colony-box under a stereo microscope, or by isolating the queen or workers in small Petri dishes. To observe living deutonymphs that were attached to a queen, she was isolated into a Petri dish about $3 \mathrm{~cm}$ in diameter. A small paper ball was offered to her as a hideaway so that she could only hide her head and parts of the anterior thorax, while the gaster and deutonymphs remained exposed to observation. The documentation of behaviors was performed using a high quality video camera (Canon $\mathrm{XL}, \mathrm{H} 13 \mathrm{CCD}$ ) and a Samsung S850. Both were connected to stereomicroscopes. Photographs were 
Wirth S. and Moser J. C.

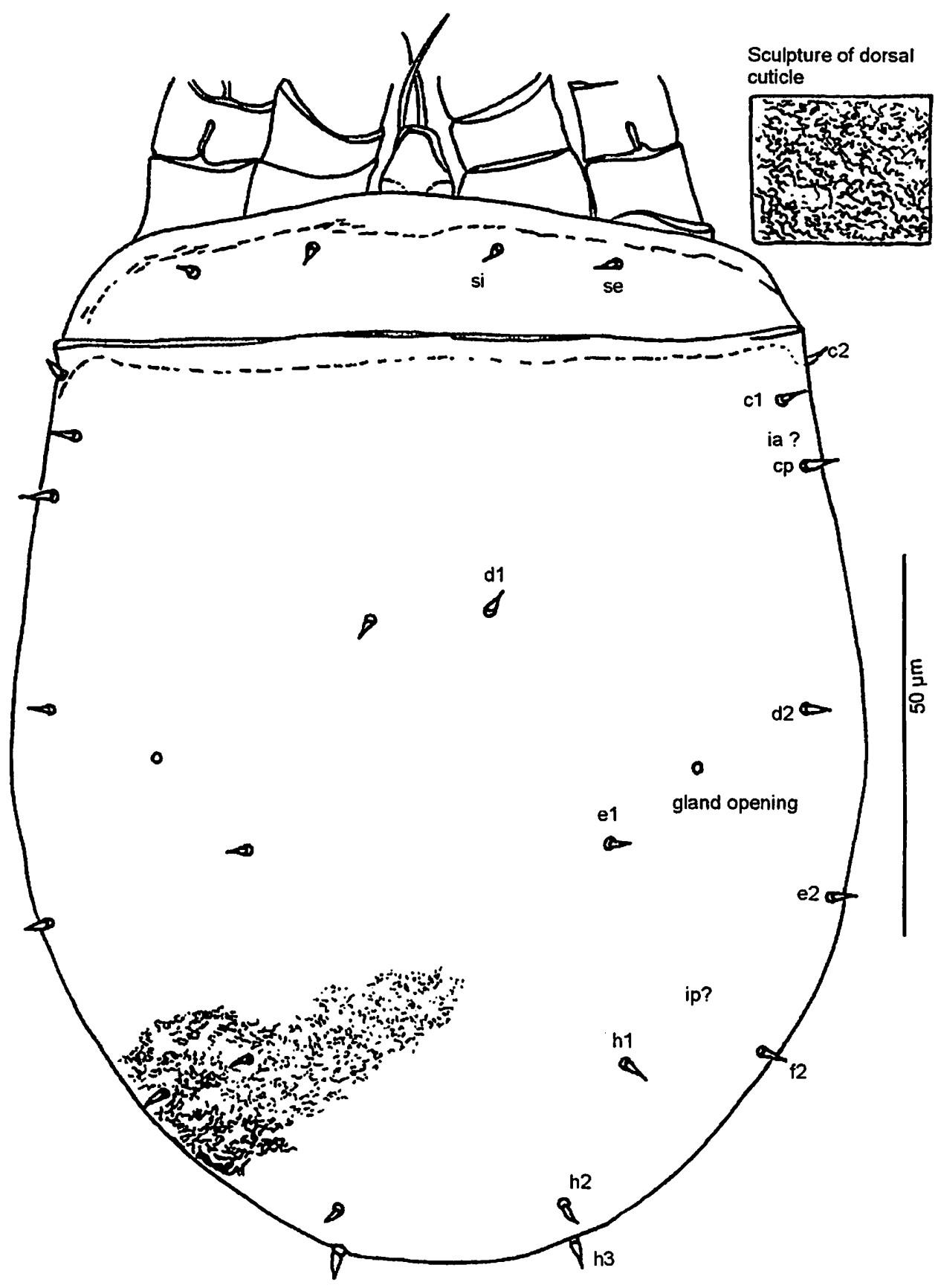

FICURE 2: Deutonymph of $H$. blomiquisti $n$. sp. in dorsal view. The reference is an SEM picture and therefore the whole shape is not as rounded as in Fig1. si, se, c1-3, d1, cp, d2, e2, f2, h1 = dorsal setae. Ia, ip = cupules, which are invisible in this deutonymph. 

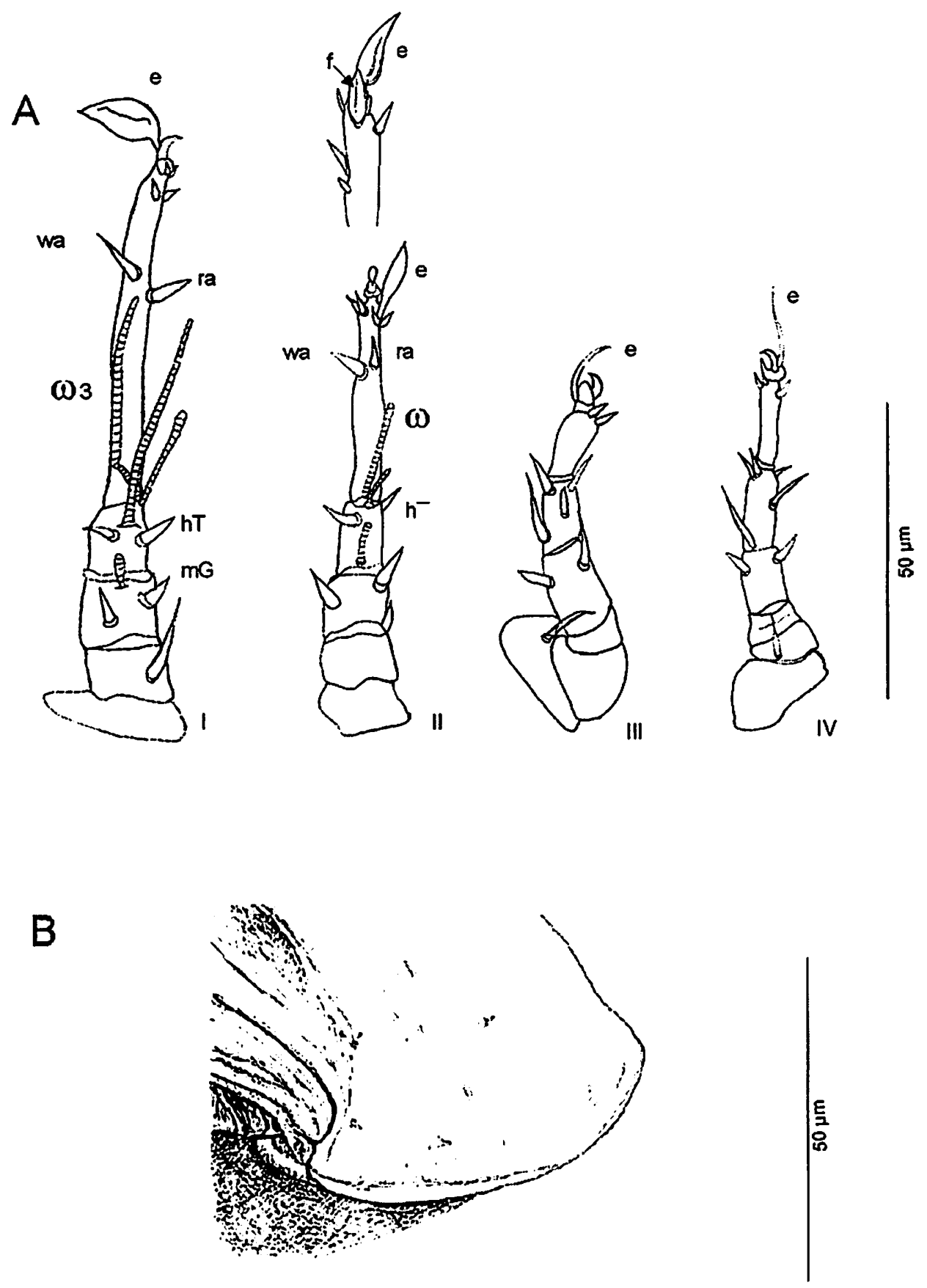

FIGURE 3: A - legs of the deutonymph of H. blomquisti n. sp. Letters designate normal setae and solenidia. The backside of the distal tarsus of leg II is depicted in higher magnification. B-drawing after a SEM picture: The lateral hysterosoma of the deutonymph forms a distinct upwards bulged ridge at its lateral margin. 

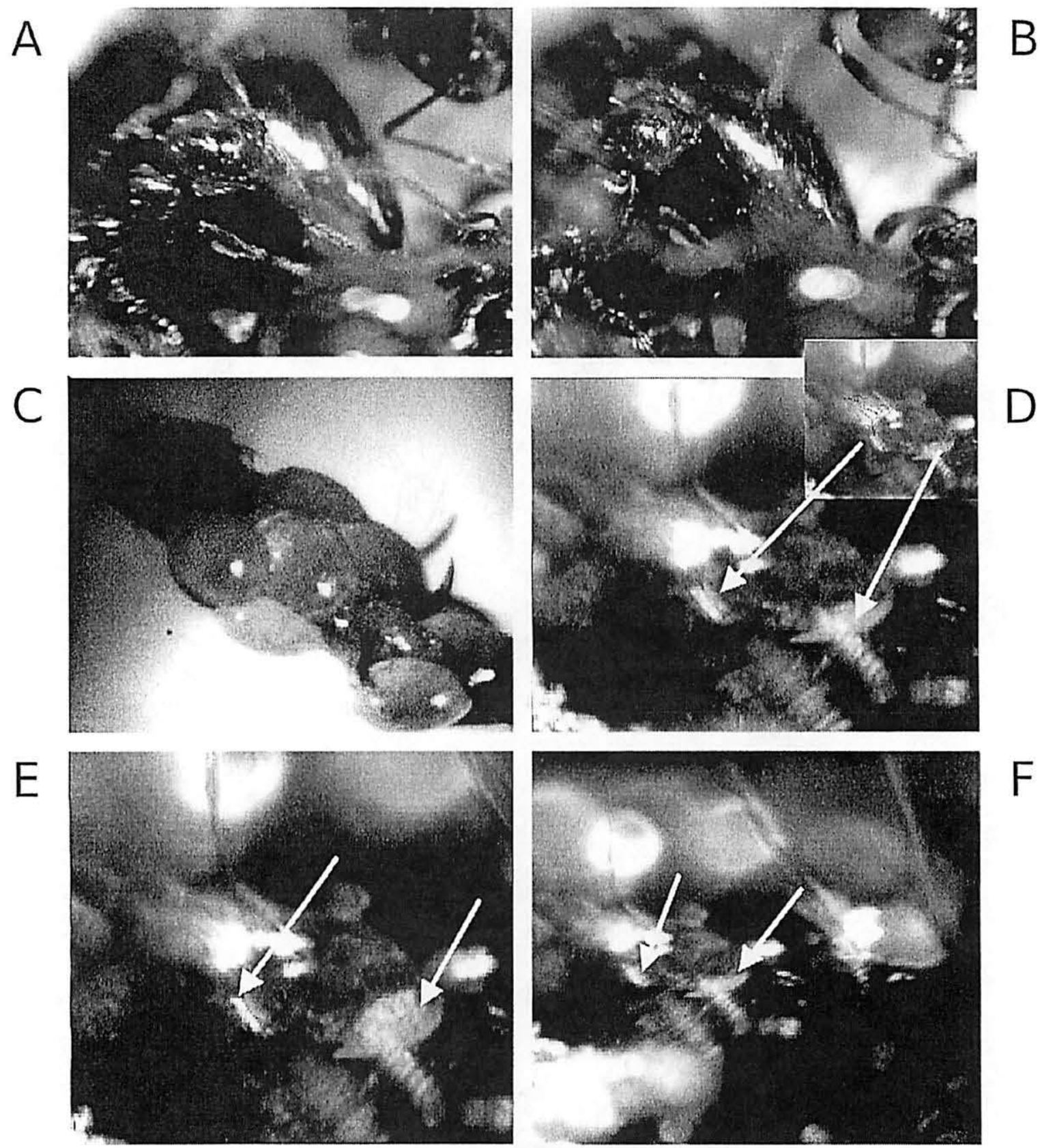

FIGURE 4: A, B - a middle-sized worker ant on the dorsum of Queen 2, which has about 85 deutonymphs attached. Its head is dropped on the surface of her gaster. Back and forth movements of this head displace deutonymphs to the more stable areas close to the intersegmental junctions. C - clusters of deutonymphs aggregated at the distal legs of a queen-cadaver. D-F - more or less transparent deutonymphs attached to the dorsal queen 2 (ca. 85 deutonymphs). D - muscles of the suckerplate contracted. Deutonymph is visible from behind and slightly laterally. Small picture right on top elucidates the outline of the barely detectable deutonymph. Upper arrow points to the dorsal area of the deutonymph. Lower arrow points to the area of visible muscle activities. E - same setting of the camera as in D, but muscles relaxed and forming in the transparent light of the trapezoid-shaped area. F-same setting as $\mathrm{D}, \mathrm{E}$, but muscles contracted again. 
exported as frames from the video files (software: Adobe premiere pro 2.0).

For Scanning Electron Microscope (SEM) studies, mites were collected from alates and queens, fixed in $90 \%$ ethanol, dried using $1,1,1,3,3$, 3,-hexamethyldisilazane and then sputtered with gold.

H. blomquisti $\mathrm{n}$. $\mathrm{sp}$. is described by its deutonymph. Although deutonymphs could be kept alive in the laboratory ant colonies, rearing adult stages has not been successful.

\section{DESCRIPTION AND RESULTS}

Holotype is a deutonymph from a queen collected by S. Wirth in Pineville, LA, in March 2009. It is mounted on a slide that is deposited together with four paratypes at the "Museum für Naturkunde" in Berlin. Several other individuals from the same locality are fixed in $95 \%$ ethanol and stored at the junior author's laboratory in Pineville, LA.

Deutonymph: Total length of dorsal idiosoma of specimens mounted on slides (from the anterior propodosoma to the posterior hysterosoma, measured medianly); mean and range of 5 specimens 139 (120-151) $\mu \mathrm{m}$. Body shape is more oval (Fig. 2), cuticle unusually soft and sclerotized. Mounted light microscopic objects show a rounded outline (Fig. 3), although it is more oval shaped in the stereomicroscope and SEM views. This phenomenon is due to the very flexible cuticle of these deutonymphs, which gets slightly deformed under pressure. The difference is made visible in the drawings of the dorsal (original shape, along the lines of a SEM picture-object, Fig. 2) and of the ventral deutonymph (along the lines of a slidemounted object, Fig. 3). Gnathosomatal remnants (= palposoma) short and wide (Fig. 3). The widest area of the palposoma in the optical section is at its half length. Palposoma is proximally wider than distally. Terminal setae are about 1.5 times as long as the total length of the palposoma and bulged medianly, either touching or crossing each other. Lateral setation invisible or absent. Only one out of four parts of the palposoma is dorsally covered by the anterior propodosoma. Propodosoma related to the hysterosoma's length conspicuously short (Fig. 2). The median anterior margin is only slightly elongated (Fig. 2). Hysterosoma about 6 times longer than the anterior-posterior length of the propodosoma; outline of hysterosoma anteriorly nearly parallel running, further posteriorly being wider and forming a rounded outline, which is slightly elongated backwards. All dorsal setae distinctly short (Fig. 2). Setae si and se on the propodosoma arranged nearly in a horizontal line with setae si positioned slightly more anteriorly. Setae $\mathrm{c} 3$ invisible in dorsal view, but visible laterally in Fig. 5F. Setae cp as usual close to setae $\mathrm{cl}$ and $\mathrm{c2}$, but at nearly the same level than setae $\mathrm{cl}$, which lay close to the lateral margin of hysterosoma. Setae d1 conspicuously close to each other with setae el beneath being positioned distinctly more laterally.

Dorsal cuticle slightly wrinkled (Fig. 2). Opisthonotal gland openings are located between $\mathrm{d} 1$ and e2. Cupules ia and ip and most ventral cupules are invisible or absent. Ventral cupules ih located laterally of the suckerplate close to the posterior margin of the deutonymph (Fig. 1).

Lateral margin of the dorsal hysterosoma bulged sideward and slightly upwards (Fig. 3B). After attaching to the ant, this lateral margin forms a close contact to the insect-surface and encloses the deutonymph's ventral side (Figs. 3B, 5E,F).

Ventral apodemes st 1 and $p 1$ free ending with st 1 ending distinctly further anteriorly than $p 1$ (Fig. 1). Apodemes $p 2$ well developed and elongated directed to conoids $c \times 3$, but not reaching $c \times 3$ and ending a bit more anteriorly. Apodemes bcx 2 medianly free ending and not -as usually in histiostomatid deutonymphs- being connected by apodemes r1, which are absent (or extremely slightly developed). Conspicuously bcx 2 and the elongations of p2 fork into two branches, which together form a "v" (Fig. 1). The "v" opens medianly. Apodeme st 2 begins at level of the posterior branch of that " $v$ "-apodeme. Apodemes $\mathrm{r} 2$ absent and $\mathrm{r} 3$ touching trochanters 4 . Apodemes $\mathrm{r} 4$ present, but medianly free, ending at level of the genital porus. Apodeme st 2 shortly interrupted in front of the genital porus. Conoids $c x 1, c \times 3$ and conoids beside the genital porus smaller than conoids of the suckerplate (Figs. 

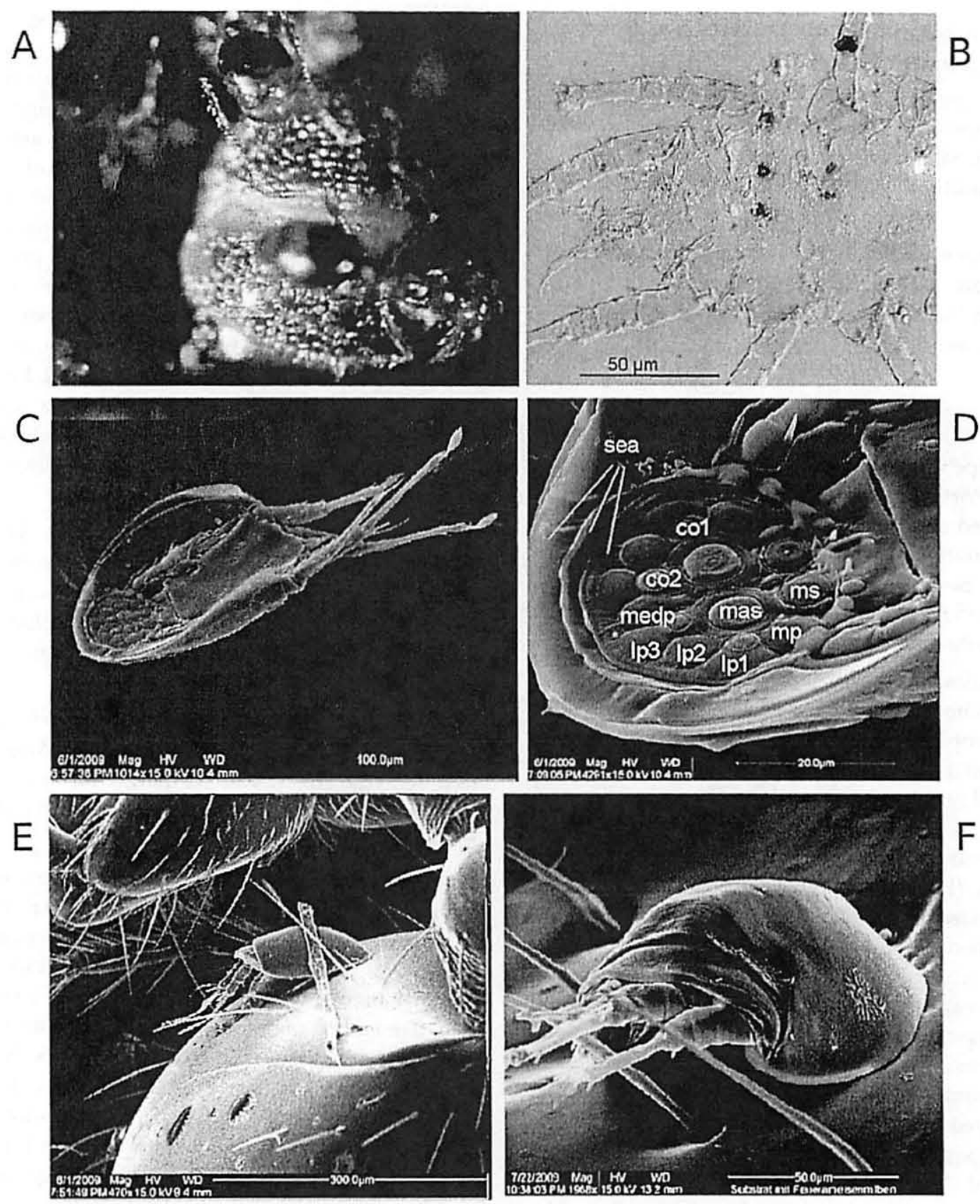

FIGURE 5: A - dorsal view on the gaster of queen 1 with 200+ deutonymphs. Middle-sized workers avoided larger deutonymph accumulations and performed rhythmical forward and backward movements (worker below on the right). B - Ventral view of a histiostomatid female that was found in the original nest soil samples of $S$, invicta. It is unknown whether this mite belongs to $H$. blomquisti n. sp. C - latero-ventral SEM view of the deutonymph of H. blomquisti $\mathrm{n}$. sp. D-suckerplate of the same deutonymph. $\mathrm{ms}=$ movable suckers, mas $=$ main suckers, $\mathrm{mp}=$ movable plate, $\mathrm{lp} 1-3=$ lateral plates, medp $=$ median plate, $\operatorname{col}-2=$ conoids, sea $=$ seams. E- deutonymph attached to the ventral head of a queen in lateral view. F-Higher magnification of the same deutonymph in a more frontal view. 
1,5C,D).

Shape of the suckerplate (Fig. 5D) is more or less round (more wide than the anterior-posterior length). Lateral margins end at the level of trochanters 4 (Fig. 3). The whole plate is located slightly apart from the posterior ending of the deutonymph's hysterosoma (Figs. 3, 5D) The suckerplate is posteriorly surrounded by three "seams", which possibly support a better fixation of the plate to the ant cuticle. The first seam is represented by the posterior margin of the suckerplate's surface itself and begins at the third lateral plates. The second seam runs parallel to the first one and possibly represents the posterior ending of the "groundplate", which is a cuticular skeleton structure underlaying the whole suckerplate. It develops to a distinct cuticular structure beginning at level of lateral "attaching plate" 1 (lp1). The third seam is represented by the ridge shaped posterior ending of the hysterosoma (Figs. 1, 5D).

All sucking structures are well developed. Their terminology follows Wirth (2004): Additionally to conoids, movable suckers and main suckers, 8 attaching plates $(4+4)$ are arranged symmetrically on each side, an additional one is unpaired and located between the posterior conoids (Figs. 1, 5D). The plate (lp1) laterally of the anterior conoids is conspicuously large developed and shapes a bulged outline, which partly encloses these conoids, while movable attaching plate $\mathrm{mp}$ laterally of the movable suckers (ms) is trapeze shaped, lp2 between anterior and posterior conoids is drop-shaped and the median attaching plate (medp) is bottle-shaped with its "neck of a bottle" pointing between the main suckers (Figs. 1, 5D).

Leg setation (Fig. 3A) in general corresponds to usual shapes and arrangements typically for Histiostomn species. Seta $f$ of leg II is flattened, leaf shaped, elongated, and partly runs along with close cuticle contact to the attaching seta $e$, which is arrow-shaped (Fig. 3A).

\section{Type-locality and type-material}

Paratypes were collected by S. Wirth from S. invictn nests in Pineville and New Orleans, LA, USA and queens attached with deutonymphs were sent by $S$.
Valles from Gainesville, FL, USA. They are added to $S$. Wirth's collection in Berlin. Additionally, many specimens collected by J. Moser are saved in his collection in Pineville (e.g. slides with numbers like 46169).

\section{Diagnosis}

Smooth and flexible translucent cuticle (Figs. 4D-F); palposoma short and wide with distal setae being 1.5 times as long as whole length of the gnathosoma and bulging inward (Fig. 2). Propodosoma conspicuously short related to the hysterosoma's length (ratio 1:6). Posterior outline of hysterosoma distinctly more rounded in shape than spiky shaped. Setae si and se nearly in a horizontal line with si positioned a bit more anteriorly. Setae $\mathrm{cl}$ positioned laterally nearly at the same level with setae cp. Setae el distinctly more laterally than $\mathrm{cl}$. Setae $\mathrm{cl}$ positioned close to each other. Cuticle slightly wrinkled (Fig. 2).

box2 and p2 forked into two branches, which form a conspicuous " $v$ ", with its opening directed medianly (Fig. 1).

Suckerplate surrounded by three distinct seams (Fig. 5D).

Leg setation: Setae e distally of tarsus I distinctly leaf-shaped and more rounded than elongated in shape. Distal claw in leg II lappet shaped and closely attached to seta e, which shapes a leaf/lappet shaped structure usually without a "shaft" (Fig. 3A).

\section{Ecology and behavior}

Insect carrier: Deutonymphs mainly attach to female alates, female dealates (Solokov et al., 2003) and queens. Queens may be heavily infested by more than 100 deutonymphs under natural conditions in the field (Fig. 5A). 
Monthly Totals of Red Imported Fire Ant Alates and Histiostoma blomquisti

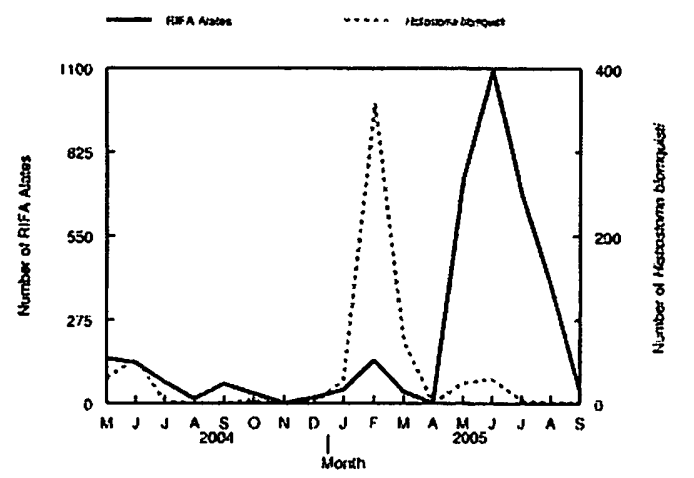

FIGURE 6: Frequency of $H$. blomquisti n. sp. Deutonymphs per ant alate (textits. invicta, $n=62$ female alates) collected in Pineville/LA/USA from a 2 months study in March and April 2009.

Female alates in the field were infested by 1 to 14 deutonymphs (Fig. 7) usually on their posterior gasters ( $n=174$ female alates in total). Of the female alates studied, $35.6 \%(=62)$ had deutonymphs with an average of 4.0 deutonymphs per female (Fig. 7). The female alates observed included both alates collected on the nest surface while awaiting mating flights and alates collected inside the mounds. Forty-three male alates were also examined. Only three of the 43 male alates each had one deutonymph attached. All of the nests sathese 4 queens, but queen 2 (Q2mpled in this study were monogyne. No dealate females were found inside the nests. Queens were found to have between 2 to over 200 deutonymphs attached to their bodies. Of the five queen specimens collected, all of the nest queens were infested. One queen was covered with over 200 deutonymphs, and the other four queens had 85, 55, 4, and 2, respectively. All queens and mites were kept in live laboratory colonies. Of the additional five queens collected and sent by $\mathrm{S}$. Valles from Gainesville, FL, USA, each had approximately 100 deutonymphs attached. The $200+$ deutonymphs on one of the queens from Louisiana were distributed all over her body, and were constantly crawling around and changing their positions (Fig. 5A). Alates and queens with deutonymph numbers less than 100 had deutonymphs attached to the dorsal thorax and the posterior gaster. They were aggregated more or less in rows along the intersegmental areas.

Habitat: The mite could not be cultured. The exact habitat of the mite's development is still unknown. A few single deutonymphs of $H$. blomquisti n. sp. were seen inside field nest samples collected in Pineville, crawling on rotting leaves and pieces of wood. This material was not very moist and only slightly covered with microorganism films. These habitats differ from typical histiostomatid habitats, which are characterized by a more moist and slimy consistency. Surfaces of such pieces of wood and decomposing leaves were the preferred habitats where feeding tritonymphs and adult females of a histiostomatid species were observed (Fig. 5B). In total, these stages were only rarely found even in these preferred habitats. Total dorsal length of these females averaged $190 \mu \mathrm{m}$. They may belong to $H$. blomquisti n. sp., but that could not be determined at this time. However, it was confirmed they are not stages of $H$. n. sp. 2 and $H$. n. sp. 3, which additionally appeared in $S$. invictn nests.

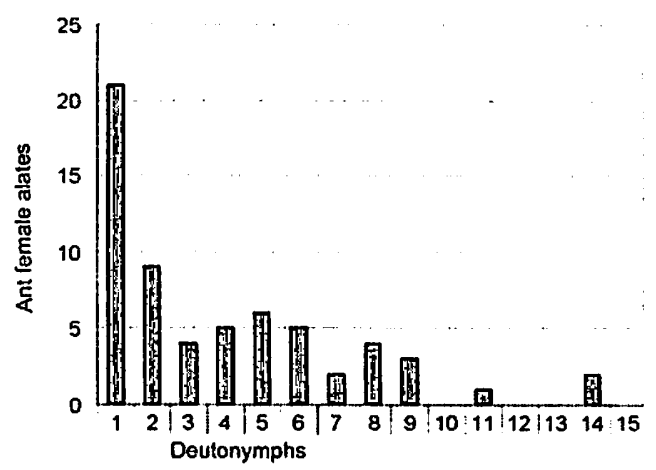

FicURE 7: Frequency of $H$. blontquisti n. sp. Deutonymphs per ant alate (textitS. invicta, $n=62$ female alates) collected in Pineville/LA/USA from a 2 months study in March and April 2009.

Longevity of deutonymphs: Deutonymphs attached to two female alates survived the death of their alates from 2-4 days to more than one month under laboratory conditions (room temperature about $22^{\circ} \mathrm{C}$ ). The cadavers of the freshly dead female alates were placed in Petri dishes $15 \mathrm{~cm}$ in diameter) lined with slightly moist paper. About 
20 deutonymphs were attached to each dead alate and remained attached to the cadavers, but changed their positions and aggregated at the distal legs of the dead ants. The deutonymphs began to cling to each other, forming clusters (Fig. 4C) of several individuals each, and adhered to one another using their sucker plates. In these positions the deutonymphs survived, in some instances, more than 4 weeks. Fungi that grew up over the ant cadavers after about 1-2 weeks apparently did not harm the deutonymphs. It appeared the fungus could not infringe on the mite bodies. Deutonymphs attached to live queens (two queens $Q 2=85$ deutonymphs, $Q 3=55$ deutonymphs) survived in laboratory colonies more than 5 months without developing.

\section{Queen cleaning behavior and how deutonymphs resist ant attacks}

Queens with high deutonymph numbers: The 200+ deutonymphs attached to queen $1(\mathrm{Q} 1)$, two female alates, and about 40 workers of different sizes were studied in a single $5-\mathrm{cm}$ diameter Petri-dish with original nest substrate. Many deutonymphs on Q1 showed much activity by crawling around on her body. A few deutonymphs switched to workers and the other two female alates, which often stayed in close body contact to the queen, during the ants apparent queen-cleaning-behavior. However, these deutonymphs occasionally switched back to the queen. Deutonymphs were attached to the queen's entire body: abdomen and thorax, ventral and dorsal head, and sections of the legs. The queen continued to produce eggs, but seemed slightly disturbed in her latitude for movement. Sometimes she was forced by her workers to a more favorable location within the laboratory colony. This behavior was not often observed in colonies with low deutonymph numbers on the queen. About 12 workers of different sizes kept close to their queen and groomed her regularly. Workers avoided areas of the queen with large mite accumulations after screening them with mandibles and antennae, and then specifically frequented areas completely without or just with a few deutonymphs for cleaning (Figs. 4A,B, 5A). In doing so, the queen's bare cuticle around the deutonymphs was licked, but deutonymphs were never removed directly using the mandibles. It was apparent that queens attracted many more deutonymphs than female alates or dealates (Solokov et al., 2003).

Additional worker behaviors took place on the queen's body. Coming from the surrounding substrate to the resting queen, workers moved their bodies forward onto the queen's gaster and back again to the substrate. These forth and back movements were repeated several times within a short time period of about 1-2 s. The deutonymphs obviously attracted these workers to perform a cleaning behavior, but when coming close to the mites, the workers suddenly retreated and repeated their approach several times again (Fig. 5A).

Within a one week period, the distribution of deutonymphs on this queen changed from all over the body to being aggregated in groups along the intersegmental areas of the tergites, and then back to being attached all over the body. Activities of the deutonymphs and close body contacts between queen and female alates apparently disturbed the deutonymphs, which changed their original positions regularly or were mechanically pushed to those intersegmental areas offering the deutonymphs a more stable hold. The cleaning behavior only rarely influenced the deutonymphs position, because the workers avoided most surface areas occupied by the mites.

Queens with low deutonymph numbers: All observed female alates and some of the queens (Q2Q5) were attacked by less than 100 deutonymphs. In these cases, the worker's cleaning activities directly influenced the positions and behaviors of deutonymphs.

The behaviors of the ants and deutonymphs were studied in the small, individual lab-colonies of these 4 queens, but queen $2(\mathrm{Q} 2)$, attached by 85 deutonymphs, and some of her workers were used as models for more detailed observations. The typical cleaning behavior is described based on a middle-sized worker. Generally the cleaning behaviors of minor, middle- sized and major workers were similar. 
At first, the worker came to the side of the queen's gaster. There it stabilized its body by pressing the hindlegs against the wall of the "observation box" and straddled legs I and II over the queen's gaster. In so doing, the left leg I clasped dorsally around the posterior gaster of the queen, while the right leg I embraced the postpetiolus. Legs II were also slightly extended and pressed against the lateral gaster. With its body fixed in this position, the worker laid its head on the surface of the queen's gaster and moved it back and forth (Figs. 4A, B). Occasionally, the worker slowly opened and closed its mandibles. These movements by the worker's relatively large mandibles pushed away the deutonymphs from their original positions, but without picking them up.

Major and middle-sized workers did not avoid smaller deutonymph aggregations $(<15)$, in contrast to the smaller workers that often climbed onto the queen's back to areas attached by none or only a few deutonymphs. The forwards and backwards cleaning movement of workers described above were also sometimes found demonstrated on queens with lower numbers of deutonymphs.

Deutonymph activities: During these ant activities, the mite deutonymphs were so tightly attached to the queen's surface, they could not be removed using a needle. However, the cleaning activities of middle-sized workers would cause the mites to shift to the posterior areas of the queen's gaster close to the intersegmental areas of the tergites. There, the deutonymphs remained in slight slots before a terminal bulge of these tergites (see also Solokov et al. 2003). This location is where deutonymphs were most often found on queens with less than 100 deutonymphs attached.

Even when not disturbed by the worker ants or other alates in the observation colony, deutonymphs were observed occasionally to be active on their queens.

Sometimes the mites would detach and walk around, remaining slightly fixed with their suckerplates, or turn their bodies around a fixed point by moving their legs. The suckerplate, which had been slightly detached to enable these movements, now became strongly attached again.
Activities of muscles that move the suckerplate and its components were made visible at a high stereo-microscope magnification and a light-beam, which went through the mite's body from anterior to posterior. Due to the unusual smooth and clear cuticle of these deutonymphs, rhythmical up and down movements of muscles and suckerplate structures became visible and could be observed (Figs. 4D-F). The suckerplate apparatus was observed to frequently move up and down by corresponding muscles for a short time immediately after the deutonymph came to rest; this obviously brought the sucking components into a suitable stable position. Plate and muscles then became visible as a trapezoid shaped structure (Fig. 4E). Deutonymphs sometimes were observed performing such muscle movements even when leg and body positions were not noticeably changed.

\section{DISCUSSION}

Sokolov ct al (2003) published the preference of this mite deutonymph for female ant dealates and alates. Here we note that there were significantly more deutonymphs on nest queens than on alates. Although other ant researchers confirmed that they often found queens covered with many deutonymphs (personal communications with $\mathrm{L}$. Hooper-Bui and W. Tschinkel), these deutonymphs were never identified.

These results indicate that $H$. blomquisti may be able to differentiate nest queens from female alates and males or workers. Past research suggests that dealates, if existing, can be differentiated from other morphs and are probably the most preferred castes related to alates (Solokov et al., 2003). Experiments to determine how the mites detect their carriers are needed. It is unknownif the deutonymphs attach to nest queens due to the longevity of queens, or if it is due to one single main-attachment-event, which could happen during the nest foundation period. The nest foundation may be a suitable situation for a mass-mite-ascending event, because there is only the queen and a few workers. There may be a possibility that the deutonymphs do not develop easily somewhere in the nest substrate (Sokolov et al., 2003). In these studies mites neither developed in 
the detritus mounds nor on cadavers in laboratorynests provided with different kinds of substrate. If some tritonymphs and adult females, which were rarely found in original nest soil samples, are determined to be $H$. blomiquisti n. sp., it might be stated that they obviously prefer rotting leaves or wooden particles with an only slightly moist, very thin film of microorganisms. Single live deutonymphs of $H$. blomquisti $\mathrm{n}$. sp. found in the same habitats additionally indicate such preferences. But because the tritonymphs and adults were rare, some additional conditions for an ideal mite-developing climate with many individuals might be required. Hence, it may be that the mite is phoretically transported by female alates to their new colonies. These ant alates are only attached by a few deutonymphs, but the numbers of deutonmyphs may be sufficient to found a new population (Wirth, 2004). Although it is not clear why these deutonymphs attach themselves to older, active queens in high numbers, it may be that, depending on climate and weather, ant colonies in the field may move around within the large ant nests to escape parts of the nest soil that becomes completely dry in the subtropical heat. Subsequently, the queen could function as an important phoretic carrier within the nest. Dealates may also carry some deutonymphs, which may switch to nest queens during close body contacts to the queen. However polygyne nests were not observed in this study. When a queen dies, the longevity of deutonymphs and the forming of clusters (Fig. $4 \mathrm{C}$ ) may be adaptations to live a longer period until suitable mite-development-conditions appear. The fact that deutonymphs live on live queens for several months may indicate that suitable conditions for mite-development do not appear often. Therefore, the deutonymphs need the queen to be able to persist longer periods. Because fungus growth on the cadavers of female alates in the experiment did not infringe on the resting deutonymphs, a fungicide effect of components produced by the deutonymphs is assumed. The origin of these components may be the opisthonotal glands which are known to have fungicide effects in some astigmatid mites (Kuwahara et al. 1989). Antifungal mite-effects could possibly benefit the ants by supporting the hygienic conditions in an ant nest.

Deutonymphs attached to a queen, alate or dealate may have a longer length of survival than deutonymph individuals in the soil or attached to dead ants. Perhaps hygienic conditions on the ants contribute to this longer period of survival. It is unknown why workers are not used commonly as carriers within the nest.

Workers obviously recognize the deutonymphs attached to their queen as foreign elements and are stimulated to cleaning activities. Cleaning activities were more intense on queens with mites than on queens without deutonymphs. Presumably allomones produced in the opisthonotal glands of the deutonymphs during such activities on queens with very large mite accumulations have a deterring effect on the workers which may explain their different behaviors on queens with few or many deutonymphs: Larger mite accumulations seem to produce more deterring components, which cause small and even middle-sized workers to retreat. Here, opisthonotal glands containing components of multiple functions may be involved (Kuwahara, 1991). The conspicuous but obviously unspecific behavior of workers hopping forth and back is interpreted as a behavior between attraction (to perform cleaning activities) and deterrent (by miteproduced components). The shape and short dorsal setation and lateral ridge of the suckerplate of deutonymphs make it difficult for workers to remove a single specimen from the backs of queens. (Figs. 3B, 5F) The suckerplate-muscle-activities of the deutonymphs and the behaviors of detaching and reattaching again may allow optimal attachment of the deutonymphs. Typical deutonymph positions on female alates and dealates seem to be influenced by the back-and-forth movements of the heads of workers during their cleaning activities. These movements by the ants push the mites into areas on the posterior tergites where the friction of the bottom layer is higher and causes a more stable fixation to the queen's cuticle.

Phylogenetic position of H. blomquisti n. sp.: Because only the deutonymph is known, enough morphological characters for a clear phylogenetic hypothesis are not available. 
The following characters of the deutonymph may indicate that perhaps this species belongs to the "Bark-inhabiting mites", which was found to be a monophyletic group within the Histiostomatidae (Wirth, 2004):

- apodemes p1 free ending: This character seems to have evolved in the stem species of the "H. piceae-group" within the "Barkinhabiting mites" (Wirth, 2004). The species therefore may be closely related to the "H. piceae-group", but characters such as "apodeme bcx2 angled to lateral" and "dorsal deutonymphal setae elongated to anterior" are missing. They could be reduced in $H$. blomquisti $\mathrm{n}$. sp. or evolved later within the " $H$. piceae-group". The reduction of elongated setae could, for instance, be evolved to persist in ant-worker-attacks to provide a smaller target for their mandibles and could be an apomorphy of this species.

- apodemes p2 clearly developed: This can be interpreted as a plesiomorphic character within all Histiostomatidae, which is commonly retained in the "Bark-inhabiting mites" and therefore also points to a possible phylogenetic position of this species within this group.

The putative adult females also possess a character of the "Bark inhabiting mites", which is the palparmembrane forming a "second ridge parallel to the cheliceral guiding structure".

\section{ACKNOWLEDGEMENTS}

We thank S. Blomquist for her general assistance in this project and dedicate this new species to her. We furthermore thank S. Valles (Gainsville, FL, USA)) for contributing queen-material of $S$. invictn and to the USDA Forestry-Service in Pineville (LA, USA) for offering work space to S. Wirth. We thank L. Hooper-Bui for introducing S. Wirth to methods of excavating whole fire ant colonies, W. Tschinkel for helpful general comments about $S$. invicta and F. Roces for helpful comments about ant behaviors.
Wirth thanks the DFG for supporting his research trip to Pineville, his parents, R. and G. Wirth, for their financial support, and to W. Sudhaus and his working group for helpful discussions.

\section{REFERENCES}

Collins H. L., Markin G. P. 1971 - Inquilines and other arthropods collected from nests of the imported fire ant, Solenopsis sacrissimn richteri - Ann. Entomol. Soc. Am. 64: 1376-80.

Creighton W. S. 1930 - The new world species of the genus Solenopsis (Hymenoptera: Formicidae - Proceedings of the American Academy of Arts and Sciences 66:39-151.

Ebermann E., Moser J. C. 2008 - Mites (Acari: Scutacaridae) associated with the red imported fire ant, Solenopsis invictn Buren (Hymenoptera: Formicidae), from Louisiana and Tennessee, U.S.A - Internat. J. Acarol 34 (1):55-69.

Khaustov A. A., Moser J. C. 2008 - Two new species of mites of the genera Petalomium Cross and Caesarodispus Mahunka (Acari: Heterostigmata: Neopygmephoridae, Microdispidae) associated with Solenopsis invicta Buren (Hymenoptera: Formicidae) from the U.S.A - Internat. J. Acarol 34 (2):115-121.

Kuwahara Y., Neal W.S., Suzuki T., Maeda M., Masutani, T. 1989 - Antifungal activity of Caloglyphus polyphyllne sex pheromone and other mite exudates Pheromone study on astigmatid mites - XXIV Naturwissenschaften 76: 578-579

Kuwahara Y. 1991 - Pheromone studies on astigmatid mites - alarm, aggregation and sex - Pp. 43-52 in DUSBABEK, F. und Bukva, V. (eds) "Modern Acarology, Vol. I", SPB Academic Publishing, The Hague.

Siebeneicher S. R., Vinson S. B., C. M. Kenerley 1992 - Infection of the red imported fire ant by Benuveria bnssiann through various routes of exposure - Journal of Invertebrate Pathology 59:280-285.

Vander Meer R. K., Wojcik D. P. 1982 - Chemical Mimicry in the myrmecophilous beetle Myrmecaphodius excavaticollis-Science, Vol. 218: 806-808.

Vazquez R. J., Porter S. D., Briano J. A. 2006 - Field release and establishment of the decapitating fly Psetidacteon curvatus on red imported fire ants in Florida BioControl, 51: 207-216.

Sokolov 1. M., Sokolova Y. Y.,Fuxa J. R. 2003 - Histiostomatid mites (Histiostomatidae: Astigmata: Acarina) from female reproductives of the red imported fire ant (Hymenoptera: Formicidae) - J. Entomol. Sci. 38: 699-702.

Wirth S. 2004 - Phylogeny, biology and character transformations of the Histiostomatidae (Acari, Astigmata) 
- Doctoral Thesis for Ph.D. Internet Publication. URL: http://www.diss.fuberlin.de/2004/312

Wirth S. 2005 - Description of a new species Bonomoin opuntiae (Histiostomatidae, Astigmata) with observations on the function of its eyes - Acarologia, vol. 45, no 4. 303-319.

Wirth S., Moser J.C. 2008 - Interactions of histiostomatid mites (Astigmata) and leafcutting ants - In: $M$. Bertrand, S. Kreiter, K.D. McCoy, A. Migeon, M. Navajas, M.-S. Tixier, L. Vial (Eds.), Integrative Acarology. Proceedings of the 6th Congress of the European Association of Acarologists., 378-384; EURAAC 2008, Montpellier, France.
Wirth S. 2009 - Necromenic life style of Histiostoma polypori (Acari, Histiostomatidae). Exp. \& app. Acarol. - DOl number: 10.1007/s10493-009-9295-6. URL:http://www.springerlink.com/openurl.asp? genre=articleandid=doi:10.1007/s10493-009-9295-6

\section{COPYRIGHT}

[(ख) cense. This open-access article is distributed under the terms of the Creative Commons-BY-NC-ND which permits unrestricted non-commercial use, distribution, and reproduction in any medium, provided the original author and source are credited. 